\title{
Experimental Assessment with Wind Turbine Emulator of Variable-Speed Wind Power Generation System using Boost Chopper Circuit of Permanent Magnet Synchronous Generator
}

\author{
Sirichai Tammaruckwattana*, Kazuhiro Ohyama ${ }^{\dagger}$, and Chenxin Yue* \\ ${ }^{*}$ Department of Electrical Engineering, Fukuoka Institute of Technology, Fukuoka, Japan
}

\begin{abstract}
This paper presents experimental results and its assessment of a variable-speed wind power generation system (VSWPGS) using permanent magnet synchronous generator (PMSG) and boost chopper circuit (BCC). Experimental results are obtained by a test bench with a wind turbine emulator (WTE). WTE reproduces the behaviors of a windmill by using servo motor drives. The mechanical torque references to drive the servo motor are calculated from the windmill wing profile, wind velocity, and windmill rotational speed. VSWPGS using PMSG and BCC has three speed control modes for the level of wind velocity to control the rotational speed of the wind turbine. The control mode for low wind velocity regulates an armature current of generator with BCC. The control mode for middle wind velocity regulates a DC link voltage with a vector-controlled inverter. The control mode for high wind velocity regulates a pitch angle of the wind turbine with a pitch angle control system. The hybrid of three control modes extends the variable-speed range. BCC simplifies the maintenance of VSWPGS while improving reliability. In addition, VSWPGS using PMSG and BCC saves cost compared with VSWPGS using a PWM converter.
\end{abstract}

Key words: Boost chopper circuit, Permanent magnet synchronous generator, Variable-speed wind generator system, Wind turbine emulator

\section{INTRODUCTION}

Wind power has become one of the most attractive energy resources for electricity production because it is virtually pollution free (if noise is not considered as pollution). Thus, a great deal of research has focused on the development of a new turbine design to reduce the cost of wind power and to make wind turbines economical and efficient. The investigation of wind power system involves high-performance wind turbine emulators (WTEs), particularly for the development of optimal control solutions. Several studies are being conducted on variable-speed wind generator systems that change the windmill rotational

Manuscript received May 20, 2014; accepted Sep. 4, 2014

Recommended for publication by Associate Editor Seung-Ho Song.

Corresponding Author: ohyama@ee.fit.ac.jp

Tel: +81-9926064682, Fax: +81-9926060751, Fukuoka Inst. of Tech.

*Dept. of Electrical Eng., Fukuoka Institute of Technology, Japan frequency in proportion to wind velocity to utilize renewable wind energy effectively by using power generating systems [1]-[6]. The energy conversion efficiency of propeller windmills depends on wind velocity and windmill speed. Therefore, a converter connected to the generator must control the windmill speed in proportion to the wind velocity to maintain the maximum energy conversion efficiency [7].

In recent years, variable-speed wind generator systems using the PWM converter (PWM converter scheme) have been introduced [3]-[6]. PWM converter is costly because many switching devices are used, and its control system is complicated. However, the variable-speed wind generator systems using PWM converters are used for variable-speed large-capacity wind generator systems that require windmill speed control.

The supply of excitation energy with a converter is not required when a permanent magnet synchronous generator (PMSG) is used. Therefore, wind generator systems using 
PMSG and a diode bridge rectifier to charge the battery are mainly operated at the rated wind velocity because the induced voltage is sufficiently high [8], [9]. These wind generator systems are low-cost converters. However, the windmill speed control is difficult to achieve because the converter cannot control the PMSG torque by itself. Furthermore, the induced voltage necessary for system interconnection cannot be obtained at low wind velocity. To date, a diode bridge rectifier scheme that realizes windmill speed control and system interconnection simultaneously at low wind velocity has not been reported.

This paper describes the experimental verification of a variable-speed wind power generation system (VSWPGS) that uses PMSG and boost chopper circuit (BCC; BCC scheme), with three speed control modes for wind velocity. The diode bridge rectifier and BCC are used as a converter. The speed control mode of low wind velocity controls the windmill speed by controlling the PMSG torque with BCC. $\mathrm{BCC}$ can control the generator torque by adjusting the armature current of PMSG. The speed control mode of middle wind velocity controls the windmill speed by controlling the PMSG torque with the system interconnection inverter. The system interconnection inverter can control the PMSG torque by adjusting the DC link voltage. The speed control mode over the rated wind velocity controls the windmill speed by controlling the windmill torque with the pitch angle control system. The pitch angle control system can control the windmill torque by adjusting the pitch angle. The extension of the variable-speed range is realized by using the hybrid control of three speed control modes. Consequently, system interconnection for all speed control modes is achieved.

\section{VARIABLE-SPEED WIND GENERATOR SYSTEM}

\section{A. System Configuration}

Fig. 1 shows the variable-speed wind power generation system. The gearless mechanism that directly connects PMSG with the windmill without using a speed-increasing gear is realized by adopting the multipole PMSG as a generator. The windmill has a pitch angle control system. The pitch angle control system is activated beyond the rated wind velocity, and the windmill rotational speed is kept at the rated windmill speed. Under the rated wind velocity, the windmill rotational speed is controlled to maintain maximum energy conversion efficiency. The converter is connected to the PWM inverter for system interconnection through the DC link condenser. The PWM inverter supplies the power system with the active power obtained from the converter side.

\section{B. Boost Converter Scheme}

Fig. 1(a) shows the VSWPGS that uses the diode bridge

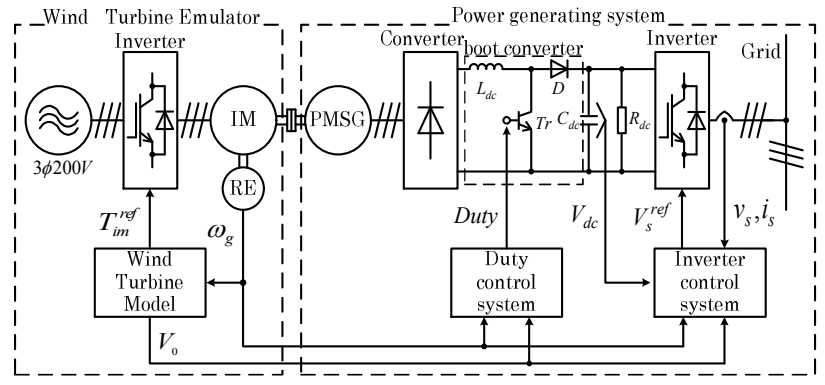

(a) Diode bridge rectifier and boost converter.

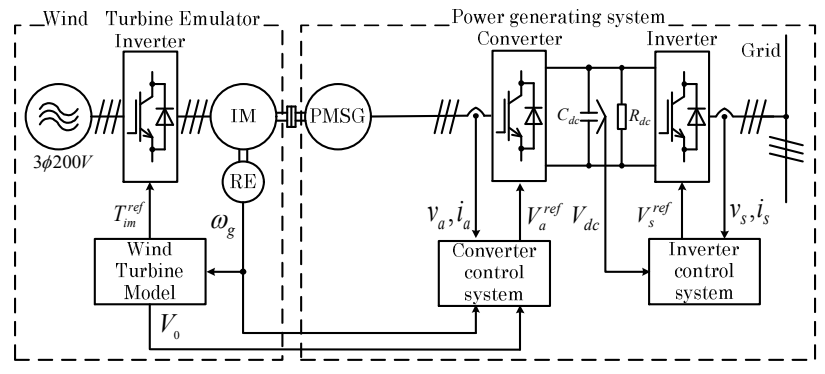

(b) PWM converter.

Fig. 1. Variable-speed wind power generator system.

rectifier and $\mathrm{BCC}$ (BCC scheme). The operation in the motoring mode cannot be obtained, because the diode bridge rectifier limits the current direction of the DC link. However, this condition does not become a problem, because the motoring mode is not used in this VSWPGS. The value of the DC link current depends on the relationship between the induced voltage of PMSG and the DC link voltage. Therefore, the diode bridge rectifier cannot control the generator torque. Therefore, BCC is added to improve its variable-speed range. BCC can control the DC link current regardless of the induced voltage value. In the low wind velocity range, in which the diode bridge rectifier cannot control the generator torque, BCC can control the generator torque by controlling the DC link current.

\section{PWM Converter Scheme}

Fig. 1(b) shows the VSWPGS that uses the PWM converter (PWM converter scheme). The PWM converter controls the windmill rotational speed by adjusting the generator torque. The PWM inverter maintains the DC link voltage to be the constant voltage necessary for the system interconnection. The PWM converter scheme can perform high-speed and high-precision generator torque control from the cut-in wind velocity to the rated wind velocity, given that the PWM converter scheme can apply the vector control system. Therefore, the frequency characteristics and variable-speed range of the windmill rotational speed control serve as a benchmark. The PWM converter scheme is referred to as a comparison object to evaluate the performance of the BCC scheme. 


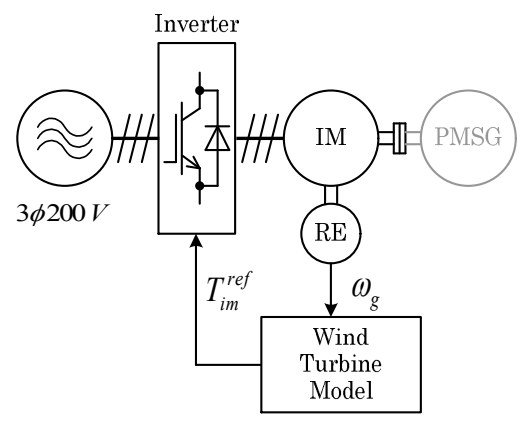

Fig. 2. WTE.

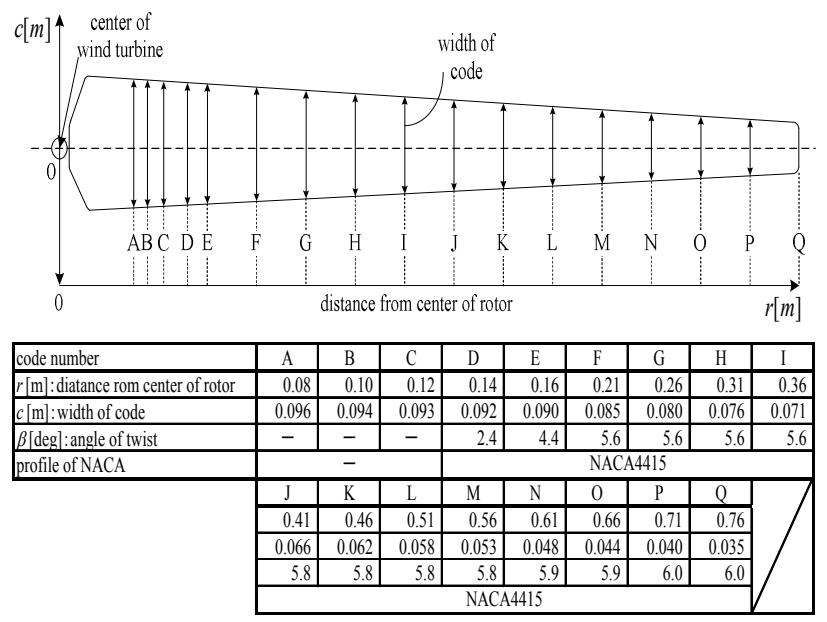

Fig. 3. Wind turbine blade shape.

\section{CONTROL SYSTEM}

\section{A. WTE}

The basic structure of the WTE is shown in Fig. 2. The wind turbine model is based on blade element momentum theory (BEMT) [8]. The wind turbine model consists of three-dimensional (3D) table data of wind turbine characteristics and the mechanical model considering the difference between real wind turbine and induction motor (IM). The $3 \mathrm{D}$ table data are composed of the torque $Q$ for wind velocity $V_{0}$ and windmill rotational speed $\omega_{r}$. The 3D data are calculated by applying the wind turbine parameters of Fig. 3 to BEMT. $V_{0}$ is provided as a condition of emulation. $\omega_{r}$ is detected with the rotary encoder (RE).

$c_{l}$ and $c_{d}$ are obtained via fluid analysis with finite element method for each point and each meeting angle from $0^{\circ}$ to $51^{\circ}$. The concrete numeric data are not given because of the space constraints. Fig. 4 shows the calculated 3D data.

\section{B. Mechanical Model}

The difference of mechanical models between real wind turbine and WTE is explained with Fig. 5. The moment of inertia and coefficient of viscosity are different between the wind turbine and IM. The differences affect the transient and steady-state responses. The differences must be compensated because wind velocity, $V_{0}$, always changes. The difference can be compensated by the following equation:

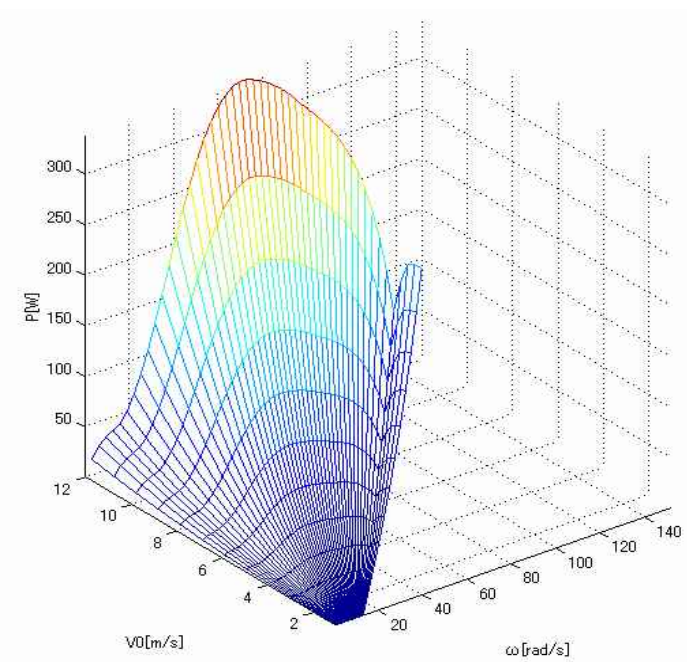

Fig. 4. 3D table data of output power.

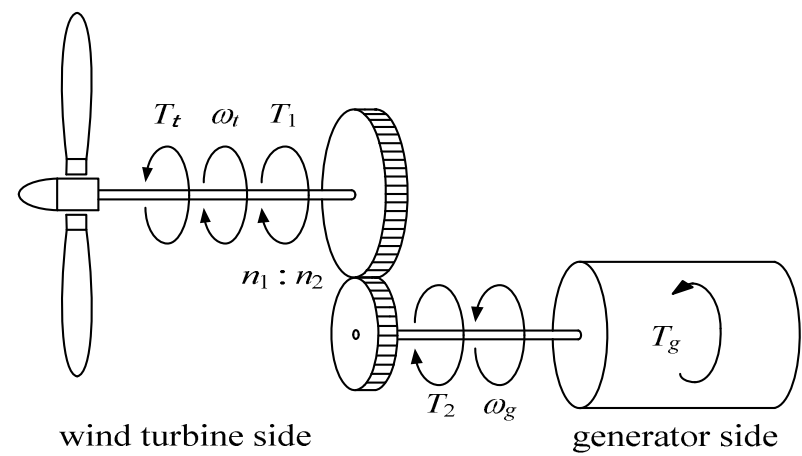

(a) Real wind turbine.

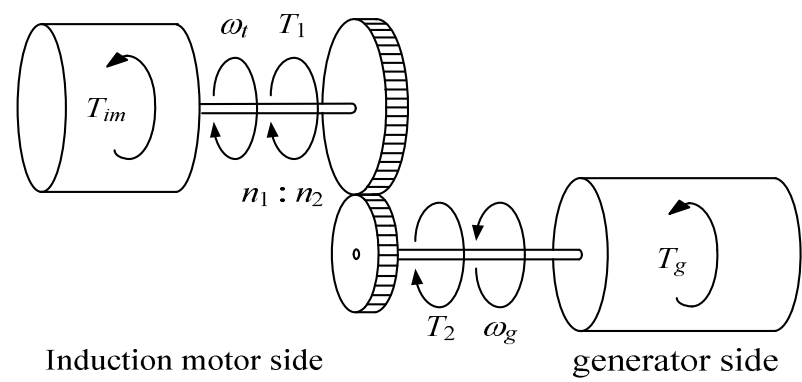

(b) WTE.

Fig. 5. Mechanical model.

$$
T_{i m}^{r e f}=\frac{J_{i m}}{J_{t}}\left(T_{t}-B_{t} \omega_{t}\right)+B_{i m} \omega_{t}
$$

where $T_{i m}{ }^{r e f}$ is the torque reference of IM $[\mathrm{Nm}], T_{t}$ is the torque of wind turbine $[\mathrm{Nm}], J_{i m}$ is the moment of inertia for IM $\left[\mathrm{kgm}^{2}\right], J_{t}$ is the moment of inertia for wind turbine $\left[\mathrm{kgm}^{2}\right], B_{\text {im }}$ is the coefficient of viscosity for IM $[\mathrm{Nm} /(\mathrm{rad} / \mathrm{s})]$, $B_{t}$ is the coefficient of viscosity for wind turbine $[\mathrm{Nm} /(\mathrm{rad} / \mathrm{s})]$, and $\omega_{t}$ is the rotational speed of WTE.

Fig. 6 shows the logic for the control of wind turbine and the steady state in which sufficient time has passed under the condition of fixed $V_{0}$. The timing of changing the control schemes is divided into Modes 1, 2, 3, and 4 . 


\begin{tabular}{|c|c|c|c|c|}
\hline mode & mode 1 & mode 2 & mode 3 & mode 4 \\
\hline pitch angle & $\begin{array}{l}\text { fixed pitch angle } \\
\quad(10[\mathrm{deg}])\end{array}$ & same & same & $\begin{array}{l}\text { Vriable pitch } \\
\text { angle }\end{array}$ \\
\hline $\begin{array}{l}\text { speed } \\
\text { reference }\end{array}$ & look up table & same & $\omega_{g}^{\max }$ & same \\
\hline $\begin{array}{l}\text { power } \\
\text { reference }\end{array}$ & look up table & same & same & $P^{r a t}$ \\
\hline $\begin{array}{l}\text { Boost } \\
\text { converter } \\
\text { method }\end{array}$ & $\begin{array}{l}\text { duty cycle } \\
\text { regulator }\end{array}$ & $\begin{array}{c}\text { speed } \\
\text { regulator }\end{array}$ & same & $\begin{array}{c}\text { pitch angle } \\
\text { regulator } \\
+ \\
\text { power regulator } \\
\text { control with } \\
\text { PWM inverter }\end{array}$ \\
\hline $\begin{array}{l}\text { PWM } \\
\text { converter } \\
\text { method }\end{array}$ & $\begin{array}{c}\text { vector control } \\
+ \\
i_{a q} \text { feedforwaed }\end{array}$ & same & same & $\begin{array}{c}\text { pitch angle } \\
\text { regulator } \\
+ \\
i_{a q} \text { feedforward } \\
+ \\
\text { power regulator } \\
\text { control with } \\
\text { PWM converter } \\
\end{array}$ \\
\hline & 1 & & & 1 \\
\hline
\end{tabular}

Fig. 6. Logic for the control of wind turbine.

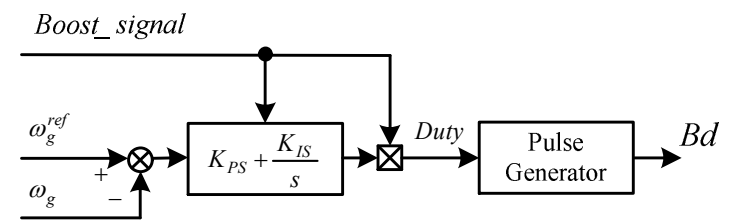

Fig. 7. Duty ratio control system for the BCC scheme.

\section{Duty Control System for the BCC Scheme [9], [10]}

Fig. 7 shows the duty ratio control system for BCC. The change of wind velocity includes the ranges of low wind velocity, middle wind velocity, and high wind velocity. For the low wind velocity, the duty control system adjusts the DC link current by controlling the BCC. The DC link current corresponds to the necessary generator torque to control windmill rotational speed. The DC link voltage is maintained at $35 \mathrm{~V}$, which is the necessary voltage for the system interconnection by the inverter, when the duty control system is switched on. The duty becomes 0 , because the DC link voltage is maintained at $35 \mathrm{~V}$ by the inverter, when the windmill speed rises and when the line voltage of PMSG exceeds $35 \mathrm{~V}$. The operating range corresponds to a middle wind velocity. Moreover, only the rectification using the reactor and diode bridge rectifier is performed.

$$
\text { Duty }=\left(K_{P S}+\frac{K_{I S}}{s}\right)\left(\omega_{g}^{r e f}-\omega_{g}\right)
$$

where $K_{P}$ is the proportional gain, and $K_{I}$ is the integral gain. Simulink model is constructed by Equation (2) and the pulse generator block, which estimates the $B_{d}$ based on Duty.

\section{Converter Control System for the PWM Converter} Scheme

Fig. 8 shows the converter control system. In the operating range under the rated wind velocity, the speed regulator is used jointly with the torque current feed-forward control. In

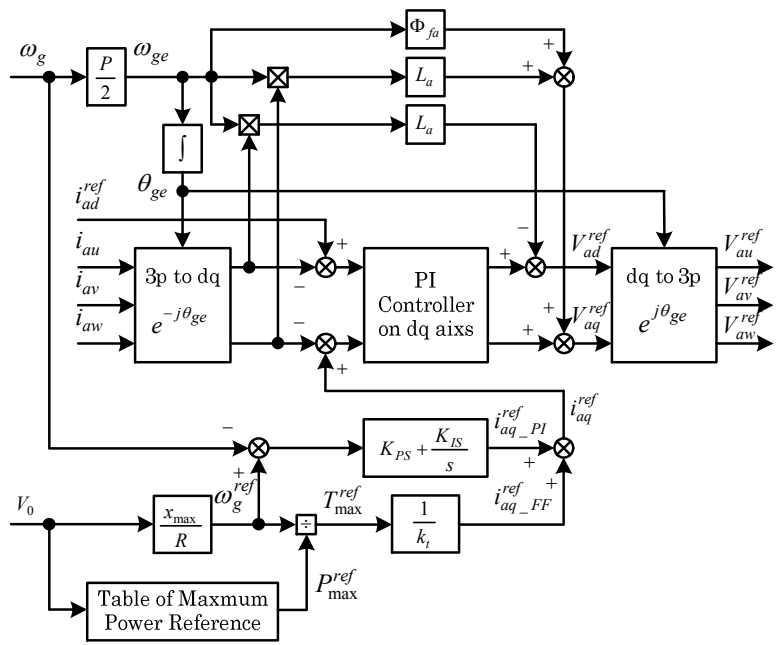

Fig. 8. Converter control system for the PWM converter scheme.

the operating range over the rated wind velocity, the pitch angle control system controls the windmill rotational speed, and the converter control system conducts the electric power control and torque current feed-forward control. The converter control system is configured by the following equations. The torque current feed-forward control is described as follows:

$$
i_{a q_{-} F F}^{r e f}=\frac{1}{P \Phi_{f a}} T_{g}^{r e f}
$$

Under the rated wind velocity, the rotational speed is controlled by regulating the torque current of PMSG. The torque current reference is calculated by the following equation of the PI controller:

$$
i_{a q_{-} P I}^{r e f}=\left(K_{P S}+\frac{K_{I S}}{s}\right)\left(\omega_{g}^{r e f}-\omega_{g}\right)
$$

Over the rated wind velocity, the windmill rotational speed is controlled by regulating the wind turbine torque. The wind turbine torque is regulated by the pitch angle control system as follows:

$$
\theta^{r e f}=\left(K_{p}+\frac{K_{I}}{s}\right)\left(\omega_{g}^{r e f}-\omega_{g}\right)
$$

Moreover, the output power is kept at the rated value by regulating the torque current of PMSG. The torque current reference is calculated by the following equation of the PI controller:

$$
i_{a q_{-} P}^{r e f}=\left(K_{P P}+\frac{K_{I P}}{s}\right)\left(P_{s}^{r e f}-P_{S}\right)
$$

The stator voltage references are calculated by the following equations:

$$
\begin{aligned}
& V_{a d}^{r e f}=\left(K_{P a d}+\frac{K_{I a d}}{s}\right)\left(i_{a d}^{r e f}-i_{a d}\right)-\omega_{g e} L_{a} i_{a q} \\
& V_{a q}^{r e f}=\left(K_{P a q}+\frac{K_{I a q}}{s}\right)\left(i_{a q}^{r e f}-i_{a q}\right)+\omega_{g e} L_{a} i_{a d}+\omega_{g e} \Phi_{f a}
\end{aligned}
$$




\section{E. Inverter Control System for the BCC Scheme}

Fig. 9 shows the inverter control system for the BCC scheme. The windmill speed control is performed by using the duty control system, when the induced voltage of PMSG is under $35 \mathrm{~V}$. Then, the inverter control system maintains the DC link voltage at $35 \mathrm{~V}$. The duty control system cannot control the windmill rotational speed when the DC link voltage exceeds $35 \mathrm{~V}$. This operating range corresponds to the ranges of middle wind velocity and high wind velocity. In a middle wind velocity under the rated wind velocity, the windmill speed control is performed with the inverter control system. Concretely, the inverter control system adjusts the electric torque of PMSG by adjusting the DC link voltage, and this system controls the windmill rotational speed. In high wind velocity, in which the wind velocity exceeds the rated wind velocity, the windmill rotational speed control is performed with the pitch angle control system. Moreover, the inverter control system performs the electric power control. The inverter control system is configured by the following equations of PI speed controller:

$$
V_{d c_{-} \omega}^{r e f}=\left(K_{P S}+\frac{K_{I S}}{s}\right)\left(\omega_{g}^{r e f}-\omega_{g}\right)
$$

Over the rated wind velocity, the rotational speed is controlled by regulating the wind turbine torque. The wind turbine torque is regulated by the pitch angle control system as follows:

$$
\theta^{r e f}=\left(K_{p}+\frac{K_{I}}{s}\right)\left(\omega_{g}^{r e f}-\omega_{g}\right)
$$

When the pitch angle control is activated, the DC link voltage reference is calculated by the following equation of PI power controller:

$$
V_{d c_{-} P}^{r e f}=\left(K_{P P}+\frac{K_{I P}}{s}\right)\left(P_{s}^{r e f}-P_{S}\right)
$$

The DC link voltage is controlled by regulating the active current. The DC link voltage reference is calculated by subtracting outputs of PI speed and power controllers from constant DC link voltage reference:

$$
i_{s d}^{r e f}=\left(K_{P V}+\frac{K_{I V}}{s}\right)\left\{V_{d c}^{r e f}-\left(V_{d c_{-} \omega}^{r e f}+V_{d c_{-} P}^{r e f}\right)-V_{d c}\right\}
$$

The reactive current reference is constant at 0 to keep the power factor at 1 . The output voltage references are calculated by using the following equations:

$$
\begin{gathered}
V_{s d}^{r e f}=\left(K_{P s d}+\frac{K_{I s d}}{s}\right)\left(i_{s d}^{r e f}-i_{s d}\right)+e_{s d}-\omega_{s} L_{s} i_{s q} \\
V_{s q}^{r e f}=\left(K_{P s q}+\frac{K_{I s q}}{s}\right)\left(i_{s q}^{r e f}-i_{s q}\right)+\omega_{s} L_{s} i_{s d}
\end{gathered}
$$

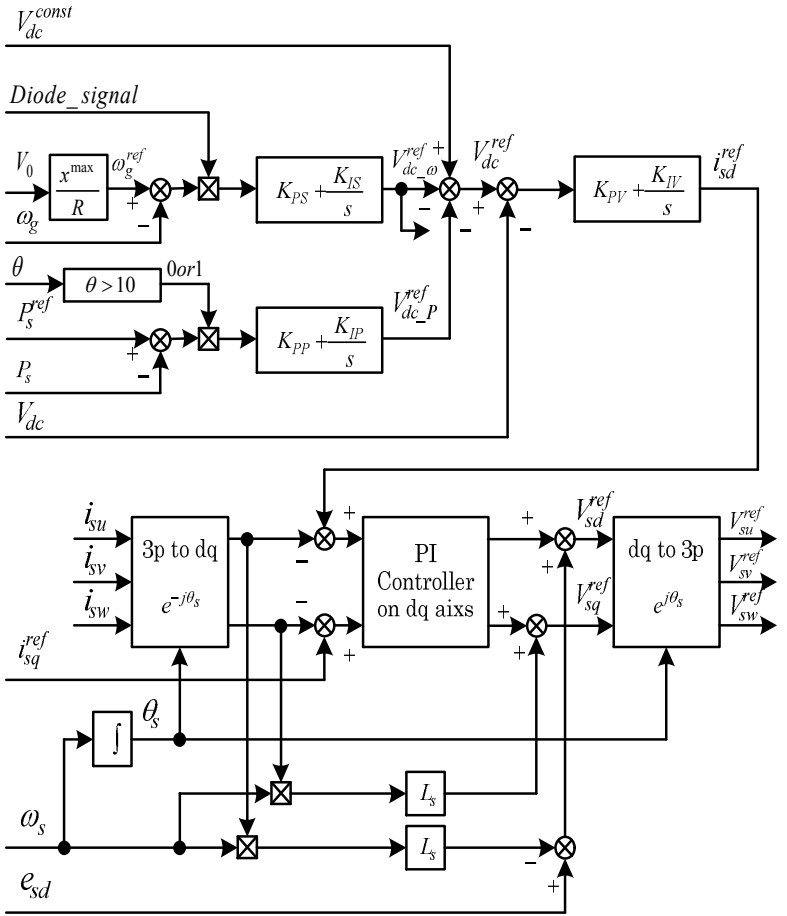

Fig. 9. Inverter control system for the BCC scheme.

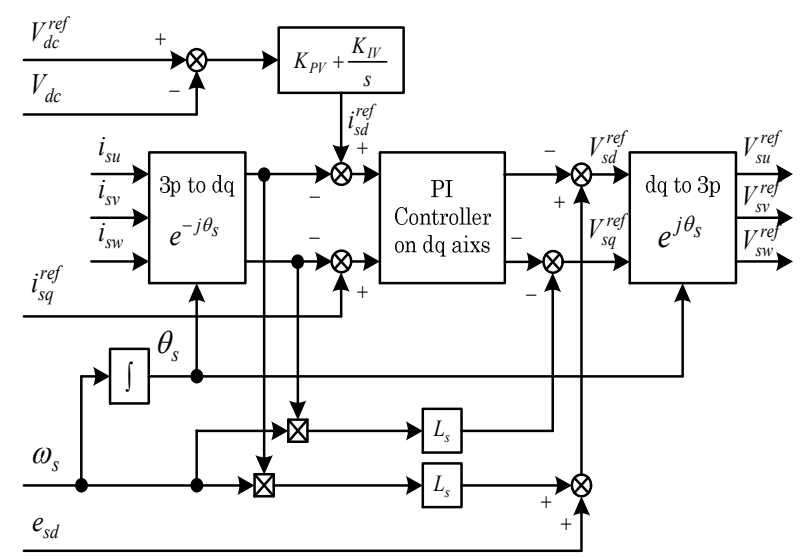

Fig. 10. Inverter control system for the PWM converter scheme.

\section{F. Inverter Control System for the PWM Converter Scheme}

Fig. 10 shows the inverter control system of the PWM converter scheme. The PWM converter scheme performs the speed control and electric power control of PMSG on the converter side. In the PWM converter scheme, the DC link voltage $V_{d c}$ is controlled at the constant of $35 \mathrm{~V}$ to perform speed control and electric power control of PMSG, whereas the system interconnection is conducted in the operating ranges of wind velocity. The $d$ axis current reference $i_{s d}{ }^{r e f}$ of Equation (12) is estimated by using the constant DC link voltage reference $V_{d c}{ }^{r e f}$ of $35 \mathrm{~V}$. Moreover, $i_{s q}{ }^{r e f}$ is set at 0 to maintain the power factor of a power system at 1 . The current controller is composed of Equations (13) and (14). 


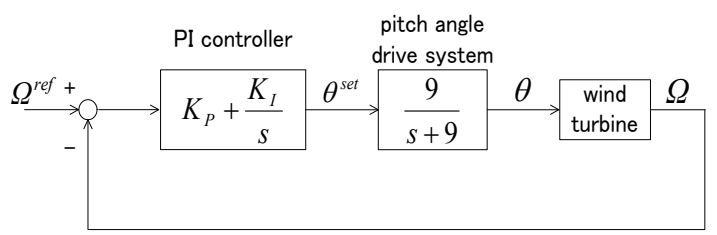

Fig. 11.- Pitch angle control system.

TABLE I

GENERATOR, POWER SYSTEM, AND TRANSFORMER PARAMETERS

\begin{tabular}{|l|l|}
\hline \multicolumn{2}{|c|}{ Permanent Magnet Synchronous Generator } \\
\hline Rated power & $300[\mathrm{~W}]$ \\
\hline Rated voltage & $200[\mathrm{~V}]$ \\
\hline Pole number & 16 \\
\hline Stator resistance & $1.419[\Omega]$ \\
\hline Stator inductance & $0.4741[\mathrm{mH}]$ \\
\hline Mutual inductance & $0.2139[\mathrm{mH}]$ \\
\hline Stator flux & $0.07293[\mathrm{~Wb}]$ \\
\hline Gear ratio & 1 \\
\hline \multicolumn{2}{|c|}{ DC link } \\
\hline Resistance & $1000[\Omega]$ \\
\hline Capacitance & $1[\mathrm{~F}]$ \\
\hline \multicolumn{2}{|c|}{} \\
\hline Line resistance & $0.01[\Omega]$ \\
\hline Line inductance system & $0.0001[\mathrm{H}]$ \\
\hline \multicolumn{2}{|c|}{} \\
\hline Output: Transformer & $\mathrm{S} 3 \mathrm{P}-240-10$ \\
\hline Type & 3 phase \\
\hline Number of phase & $0-240[\mathrm{~V}]$ \\
\hline Output voltage & $5 \%$ or less \\
\hline Voltage fluctuation rate & $20[\mathrm{~A}]$ \\
\hline Allowable current & $3.46[\mathrm{KVA}]$ \\
\hline Capacity & $200[\mathrm{~V}]$ \\
\hline Input: & $50 / 60[\mathrm{~Hz}]$ \\
\hline Input voltage & \\
\hline Input frequency & \\
\hline
\end{tabular}

\section{G. Pitch angle control system}

Fig. 11 shows the block diagram of the pitch angle control system. The model of the pitch angle drive system describes the response of the displacement servo system and the hydraulic cylinder. This model is described as the first-order lag element, because the hydraulic cylinder has integral characteristics and because it becomes the response of the closed-loop system that comprises the servo gain. The time constant of the first-order lag element is the time constant of the pitch angle control system adopted for the wind generation system.

Table I shows the generator and power system parameters. The parameters of PMSG, power system, and transformer are common. Table II shows the control parameters for the BCC scheme. The control parameters of the boost converter and duty control system are designed with the simulations by using the implemented Simulink models. The control parameters of the vector control system applied in the inverter side are

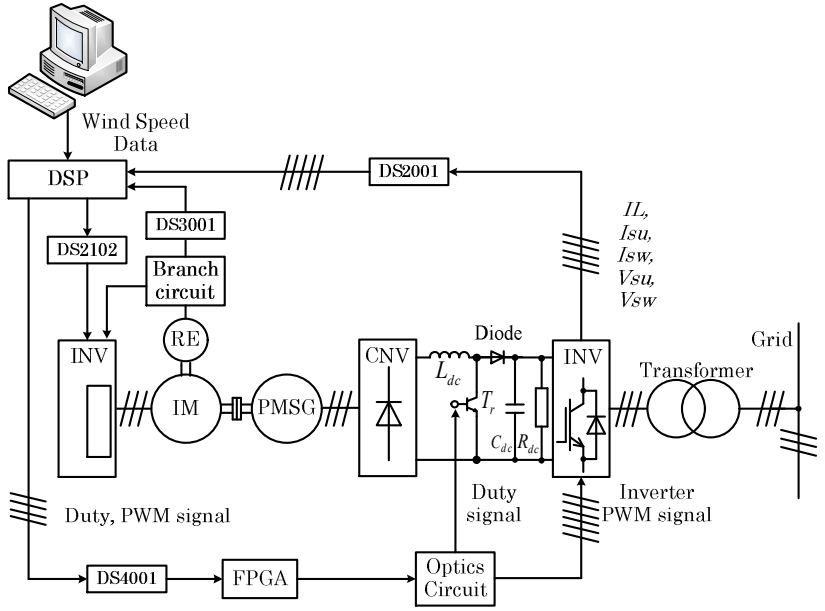

(a) BCC scheme.

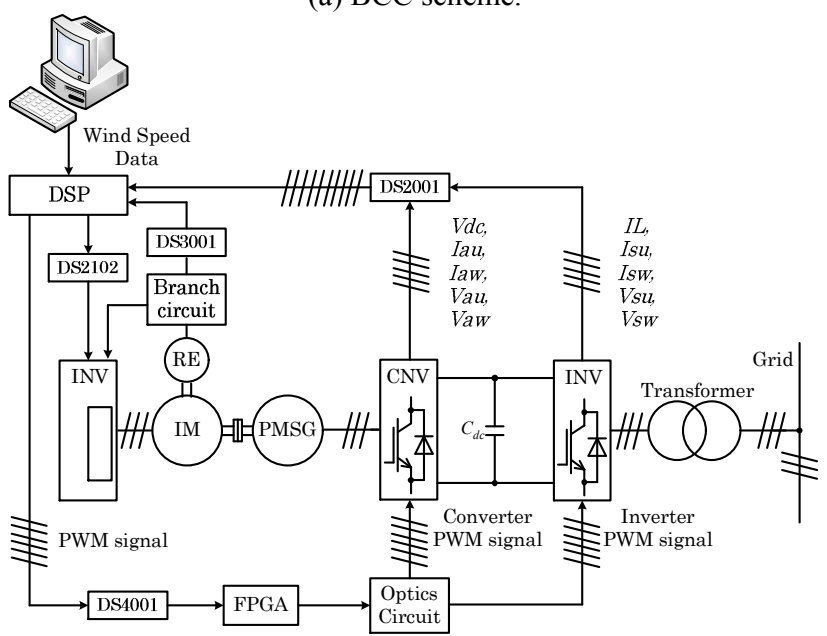

(b) PWM converter scheme.

Fig. 12. Experimental system.

designed with the conventional method that considers the arrangement of pole and zero based on the control theory. Table III shows the control parameters of the PWM converter scheme. The control parameters of the vector control system applied in the converter and inverter sides are designed with the conventional method that considers the arrangement of pole and zero.

\section{EXPERIMENTAL SYSTEM}

Fig. 12 shows the experimental system of the BCC and PWM converter schemes. The digital signal processing (DSP) unit calculates the wind turbine torque reference from the wind velocity data and rotational speed of the IM. The wind velocity data are provided by the stored data in a PC. The rotational speed of IM is estimated in the DSP by using the signals from the RE. The torque of IM is controlled by the off-the-shelf inverter. The IM is operated based on the wind turbine torque reference sent from a DSP through the D/A board (DS2102). After the WTE is activated, the PMSG starts to rotate, and the converter control system starts to control the 
TABLE II

Control Parameters of Boost CONVERTER

\begin{tabular}{|l|l|}
\hline \multicolumn{2}{|c|}{ Boost Convertor System } \\
\hline Inductance of boost convertor circuit & $1[\mathrm{mH}]$ \\
\hline \multicolumn{2}{|c|}{ Duty Cycle controller } \\
\hline Proportional gain of speed regurator & 20 \\
\hline Integral gain of speed regurator & 100 \\
\hline Switching frequency & $1[\mathrm{kHz}]$ \\
\hline \multicolumn{2}{|c|}{ Vector controller for Invertor } \\
\hline Proportional gain of DC link voltage regurator & -100 \\
\hline Integral gain of DC link voltage regurator & -500 \\
\hline Proportional gain of speed regurator & 1 \\
\hline Integral gain of speed regurator & 500 \\
\hline Proportional gain of maxmum power regurator & 0.000001 \\
\hline Integral gain of maxmum power regurator & 0.001 \\
\hline Proportional gain of d axis current regurator & $6.24 / 206$ \\
\hline Integral gain of d axis current regurator & 6.24 \\
\hline Proportional gain of q axis current regurator & $6.24 / 206$ \\
\hline Integral gain of q axis current regurator & 6.24 \\
\hline Setting of phase voltage & $100 /$ sqrt $(3)$ \\
\hline DC link voltage reference & 35 \\
\hline \multicolumn{2}{|c|}{ Pitch angle control } \\
\hline Proportional gain of speed regurator & 5 \\
\hline Integral gain of speed regurator & 10 \\
\hline
\end{tabular}

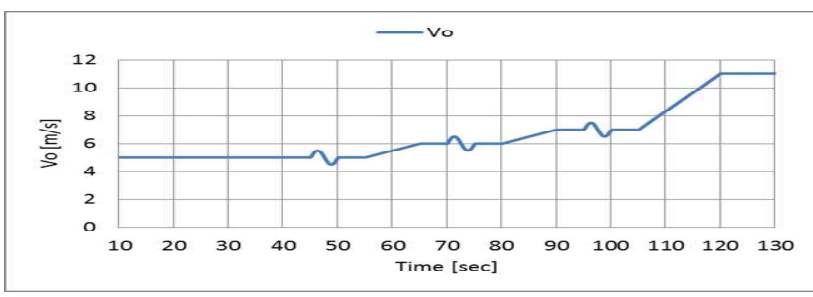

Fig. 13. Change of wind velocity.

windmill rotational speed for the maximum power point tracking. The duty and PWM signals that control the duty and INV are sent from a DSP to the short-circuit prevention circuit through a digital IO board (DS4002). The PWM signals are sent to the $\mathrm{CNV}$ and INV through the optical circuit.

Fig. 13 shows the change of the wind velocity $V_{0}[\mathrm{~m} / \mathrm{s}]$ and includes each mode shown in Fig. 6. The change of wind velocity includes the ranges of low wind velocity at $5 \mathrm{~m} / \mathrm{s}$, which corresponds to Mode 1 , wind velocity at $6 \mathrm{~m} / \mathrm{s}$, which corresponds to the switching point between Modes 2 and 3, middle wind velocity at $7 \mathrm{~m} / \mathrm{s}$, which corresponds to Mode 2 and Mode 3, and high wind velocity at $11 \mathrm{~m} / \mathrm{s}$, which corresponds to Mode 4. High wind velocity denotes the wind velocity that exceeds the rated value. All ranges include the sinusoidal change of amplitude: $0.5[\mathrm{~m} / \mathrm{s}]$ and $0.2[\mathrm{~Hz}]$. The $\mathrm{BCC}$ and PWM converter schemes are tested for the same change of the wind velocity, and the control performances of both schemes are discussed.
TABLE III

CONTROL PARAmeters OF PWM CONVERTER

\begin{tabular}{|l|l|}
\hline \multicolumn{2}{|c|}{ PWM Cnvertor System } \\
\hline \multicolumn{2}{|c|}{ Vector controller for Convertor } \\
\hline Proportional gain of speed regurator & $100 / 3.12$ \\
\hline Integral gain of speed regurator & 100 \\
\hline Proportional gain of maxmum power regurator & 0.000001 \\
\hline Integral gain of maxmum power regurator & 0.001 \\
\hline Proportional gain of d axis current regurator & $225 / 315$ \\
\hline Integral gain of d axis current regurator & 225 \\
\hline Proportional gain of q axis current regurator & $225 / 315$ \\
\hline Integral gain of q axis current regurator & 225 \\
\hline Setting of stator flux & 0.07293 \\
\hline \multicolumn{2}{|c|}{ Vector controller for Invertor } \\
\hline Proportional gain of DC link voltage regurator & -5 \\
\hline Integral gain of DC link voltage regurator & 100 \\
\hline Proportional gain of d axis current regurator & $25 / 357$ \\
\hline Integral gain of d axis current regurator & 25 \\
\hline Proportional gain of q axis current regurator & $25 / 357$ \\
\hline Integral gain of q axis current regurator & 25 \\
\hline Setting of phase voltage & $100 /$ sqrt(3) \\
\hline DC link voltage reference & 35 \\
\hline \multicolumn{2}{|c|}{ Pitch angle control } \\
\hline Proportional gain of speed regurator & 5 \\
\hline Integral gain of speed regurator & 10 \\
\hline
\end{tabular}

Figs. 14 and 15 show the experimental results of the BCC scheme. The system activates at $5 \mathrm{~m} / \mathrm{s}$, which exceeds the cut-in wind velocity of $3 \mathrm{~m} / \mathrm{s}$, and the power generation started after approximately 9 seconds, in which windmill speed $\omega_{g}$ reaches the windmill rotational speed reference $\omega_{g}{ }^{r e f}$. In the wind velocity of $5 \mathrm{~m} / \mathrm{s}$, which corresponds to Mode 1 , the speed control is performed by the duty control system. Fig. 14 illustrates that windmill speed $\omega_{g}$ and duty can confirm that the speed control is well performed. Fig. 15 illustrates that $\omega_{g}$, duty, and DC link voltage $V_{d c}$ can confirm that the speed control is performed while the speed control system is smoothly switched at the wind velocity of $6 \mathrm{~m} / \mathrm{s}$, which corresponds to the switching point of Modes 2 and 3. At the wind velocity of $7 \mathrm{~m} / \mathrm{s}$, which corresponds to Mode 3 , the speed control is performed by adjusting $V_{d c}$ with the inverter control system. $\omega_{g}$ and $V_{d c}$ can confirm that the speed control is well performed. In wind velocity of $11 \mathrm{~m} / \mathrm{s}$, which corresponds to Mode 4, the speed control is performed by pitch angle control system, and the electric power control is conducted by the inverter control system. Fig. 15 illustrates that $\omega_{g}, V_{d c}$, and pitch angle $\theta$ can confirm that $\omega_{g}$ is controlled at the rated speed and that the generated power $P_{s}$ is controlled at the rated power of $300 \mathrm{~W}$.

Figs. 16 and 17 show the simulation results of the PWM converter scheme. The system activates at the wind velocity of $5 \mathrm{~m} / \mathrm{s}$, which exceeds the cut-in wind velocity of $3 \mathrm{~m} / \mathrm{s}$. Moreover, the power generation started after approximately 11 


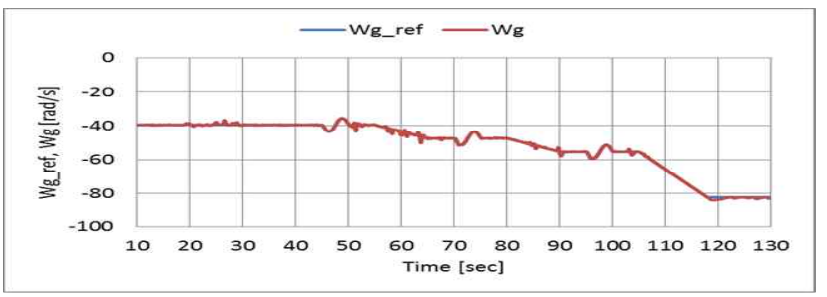

(a) Rotational speed reference and rotational speed.

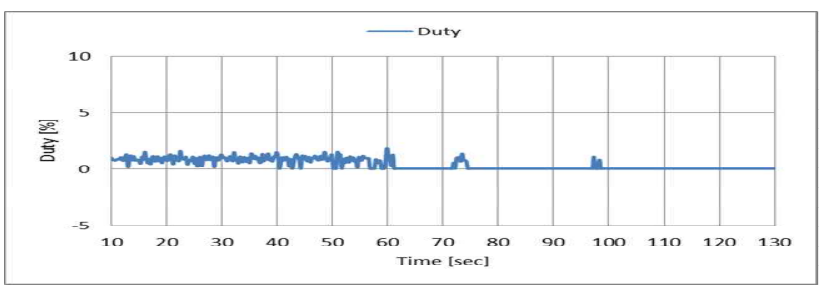

(b) Duty control signal.

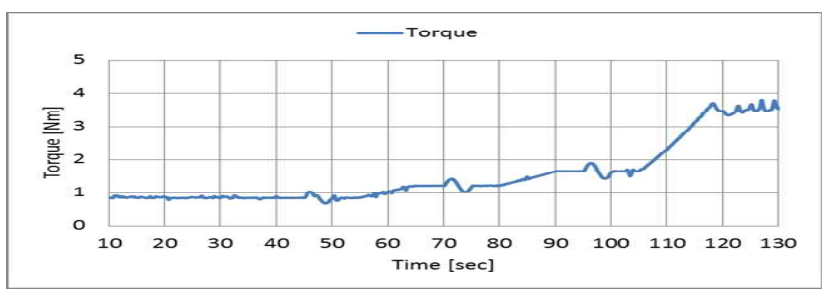

(c) Wind turbine torque.

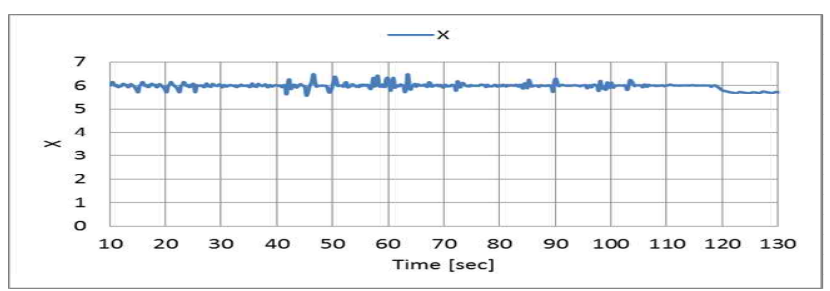

(d) Tip speed ratio.

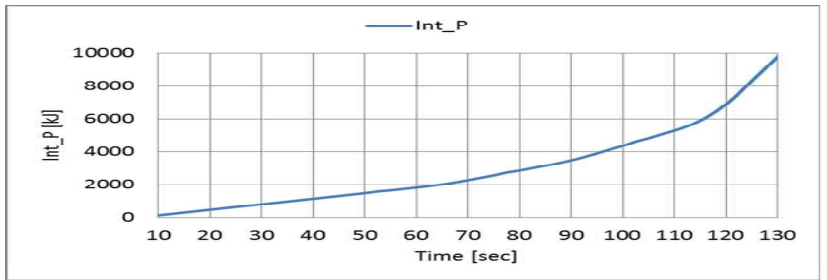

(e) Integrated power system.

Fig. 14. Experimental results of the BCC scheme.

seconds, in which $\omega_{g}$ reaches in $\omega_{g}^{r e f}$ as well as the BCC scheme. The system is operated under the rated wind velocity, which corresponds to Modes 1 to 3 until about 115 seconds. Thus, $\omega_{g}$ follows $\omega_{g}{ }^{r e f}$. However, the response of the PWM converter scheme has been retarded because the increase of $\omega_{g}{ }^{r e f}$ corresponds to the increase of wind velocity given that the restriction of torque current reference $i_{a q}{ }^{\text {ref }}$ has been established so that PMSG may not conduct the motoring. The operating range, which exceeds the rated wind velocity and corresponds to Mode 4, starts after 115 seconds. The pitch angle control system starts around 118 seconds. Then, the speed controller of converter control system stops

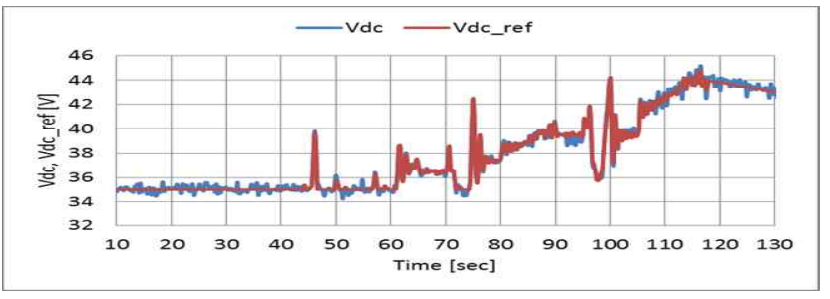

(a) DC link voltage and its reference.

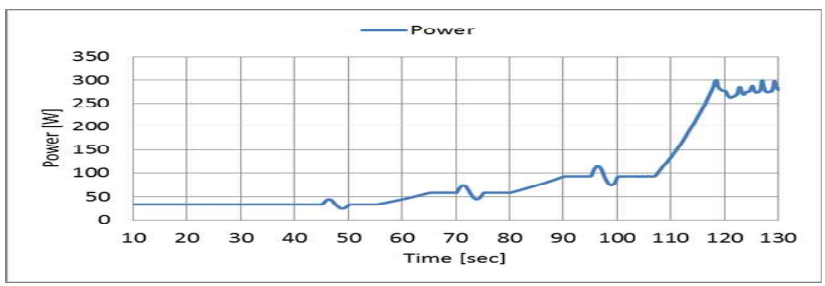

(b) System power.

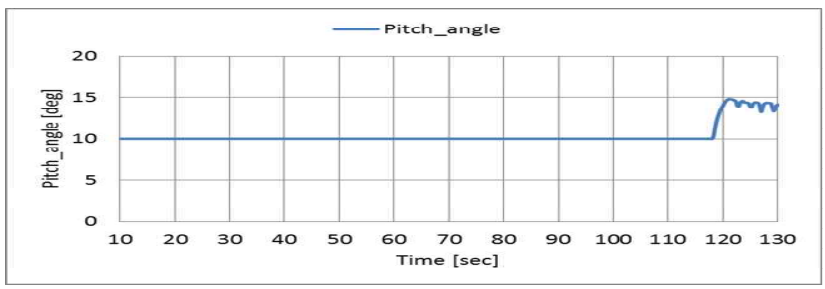

(c) Pitch angle control.

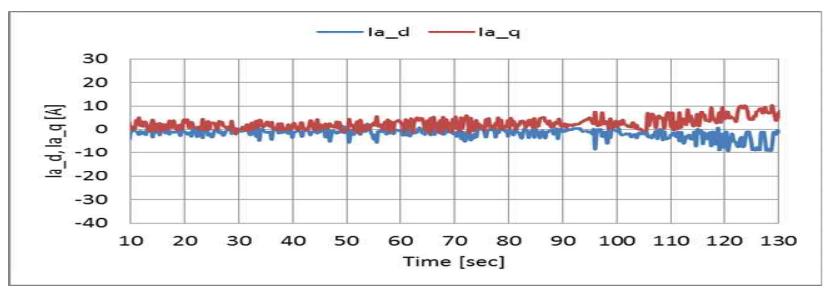

(d) $d$ axis and $q$ axis current.

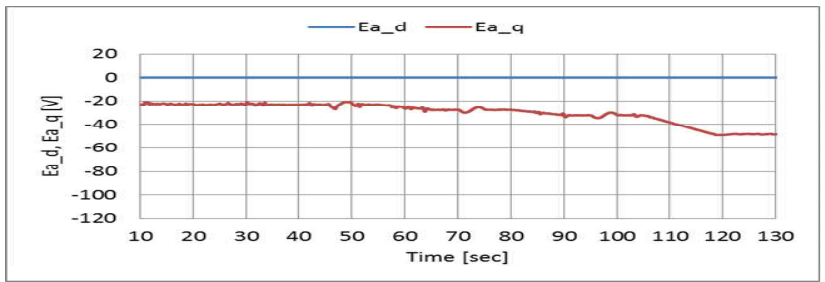

(e) $d$ axis and $q$ axis voltage.

Fig. 15. Experimental results of the BCC scheme.

simultaneously, and the maximum electric power tracking control is activated. The sinusoidal change of wind velocity is superimposed in this operating range. $\omega_{g}$ is maintained at the rated speed-by-speed control by pitch angle control system and the electric power control by converter control system. Moreover, the generated output $P_{s}$ is maintained at the rated power of $300 \mathrm{~W}$.

Table IV shows the integrated powers of each mode of the BCC and PWM converter schemes. Integrated $P_{s}$ of the BCC scheme decreases at 0 seconds to 55 seconds, which corresponds to Mode 1, compared with integrated $P_{s}$ of the PWM converter scheme, because the tracking characteristic 


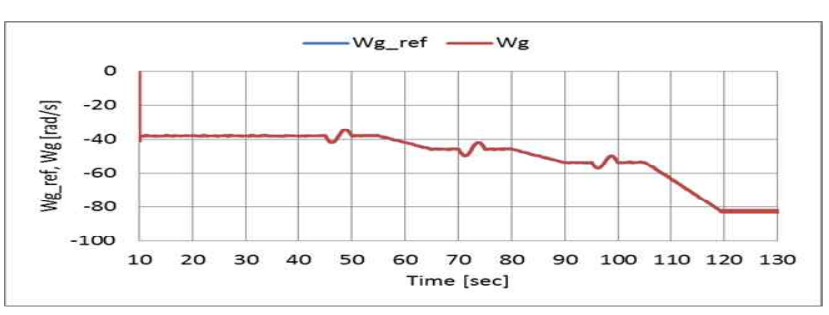

(a) Rotational speed reference and rotational speed.

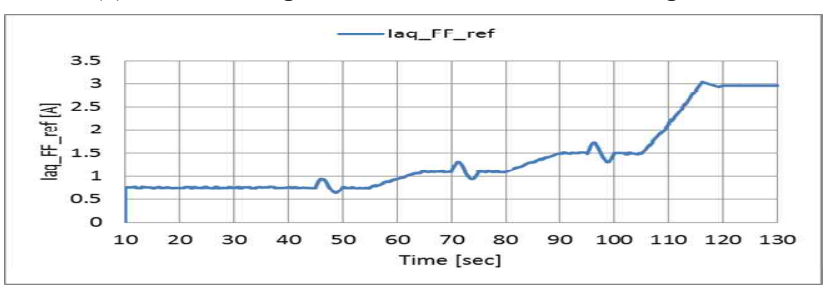

(b) $q$-axis current reference of feed-forward control.

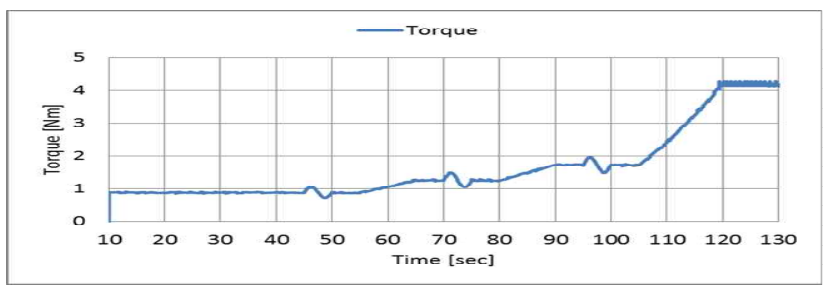

(c) Wind turbine torque.

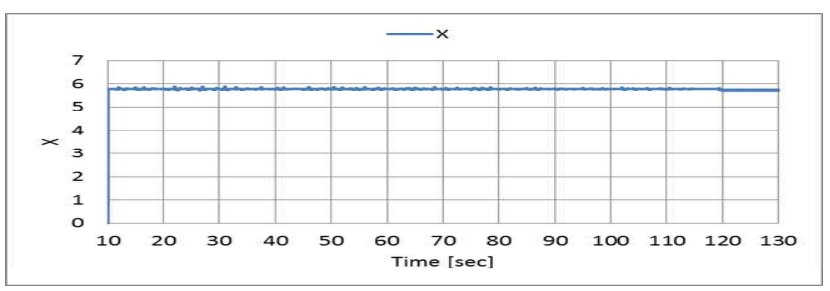

(d) Tip speed ratio.

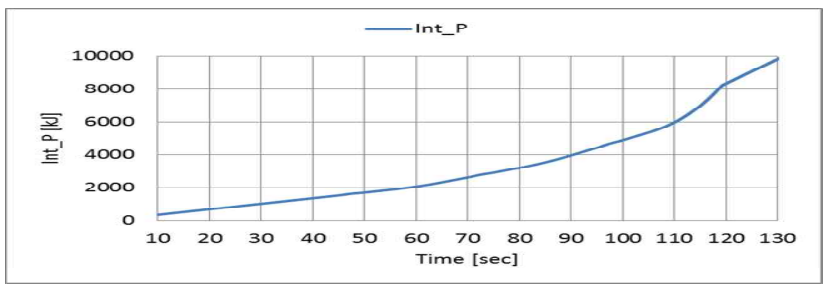

(e) Integrated power system.

Fig. 16. Experimental result of the PWM converter scheme.

of $\omega_{g}$ for $\omega_{g}{ }^{r e f}$ is inferior. The BCC scheme uses the hybrid control of the duty control system and speed control of the inverter side at 55 seconds to 80 seconds, which corresponds to the switching point of Modes 1 and 2. In this operating range, integrated $P_{s}$ of the BCC scheme decreases, because the tracking characteristic of the speed reference is inferior to the PWM converter scheme. The BCC scheme charges the DC link condenser at 80 seconds to 105 seconds, which corresponds to Mode 3. Therefore, integrated $P_{s}$ decreases. In this period, speed control is performed by charging the DC link condenser, given that the wind velocity increases. Integrated $P_{s}$ of the $\mathrm{BCC}$ scheme and the PWM converter

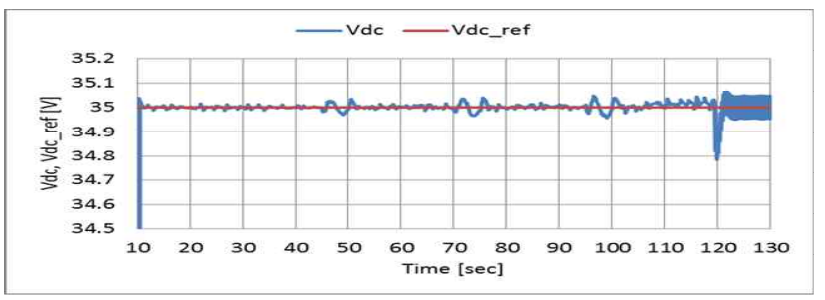

(a) DC link voltage and its reference.

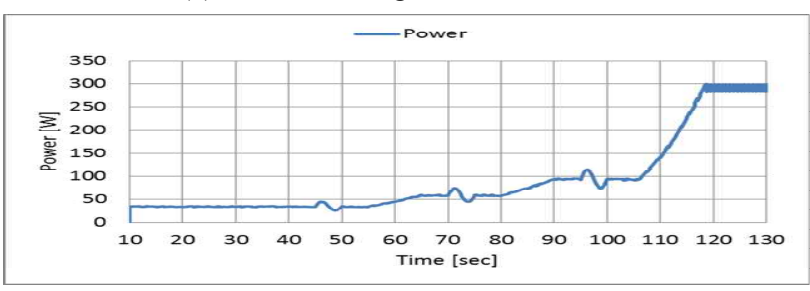

(b) System power.

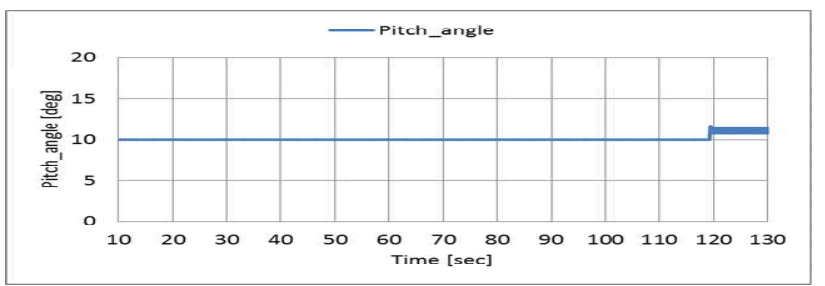

(c) Pitch angle control.

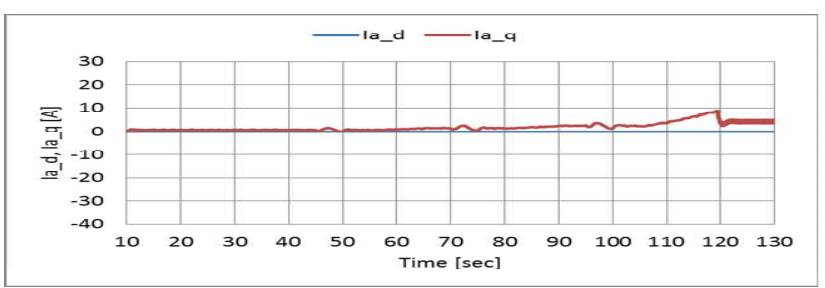

(d) $d$ axis and $q$ axis current for converter side.

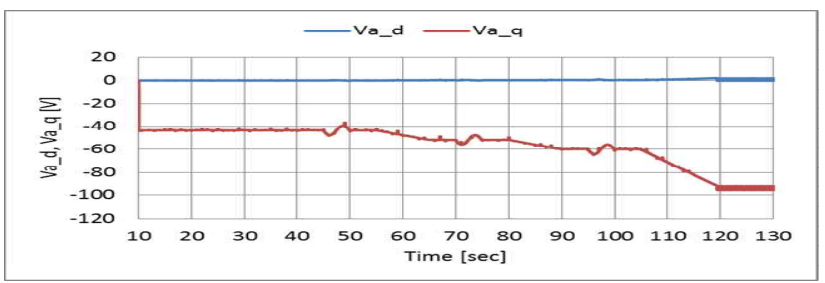

(e) $d$ axis and $q$ axis voltage.

Fig. 17. Experimental result of the PWM converter scheme.

TABLE IV

INTEGRATEd Power of EACH Mode

\begin{tabular}{|c|c|c|c|}
\hline Mode & Time[sec] & $\begin{array}{c}\text { Integrated electric power } \\
\text { in kJ for Boost } \\
\text { Converter system }\end{array}$ & $\begin{array}{c}\text { Integrated electric power } \\
\text { in kJ for PWM } \\
\text { Converter system }\end{array}$ \\
\hline mode1 & $0-55[\mathrm{sec}]$ & $0-1647$ & $0-1859$ \\
\hline mode1 or mode2 & $55-80[\mathrm{sec}]$ & $1647-2861$ & $1859-3197$ \\
\hline mode3 & $80-105[\mathrm{sec}]$ & $2861-4817$ & $3197-5344$ \\
\hline mode4 & $105-130[\mathrm{sec}]$ & $4817-9785$ & $5344-9813$ \\
\hline
\end{tabular}

scheme have a significant difference, given that the DC link capacitor of the BCC scheme discharges in the operating range of 105 seconds to 130 seconds, which exceeds the rated wind velocity and corresponds to Mode 4. At this operating 
range, the pitch angle control is activated, and the efficiency of the converter of the BCC scheme changes because the operating circuit changes for the operating modes.

\section{CONCLUSIONS}

This paper proposed the VSWPGS using the BCC scheme. An implementation process that considers all systems for the BCC scheme was proposed to verify the validity. In addition, the implementation process of the VSWPGS using the PWM converter scheme was described as the benchmark comparison. The experimental systems of both schemes were built to evaluate the performance of the BCC scheme. The BCC scheme enabled windmill rotational speed control from the cut-in wind velocity to the overrated wind velocity. Therefore, the BCC scheme obtained a performance similar to that of the PWM converter scheme. The developed WTE can be used to analyze various mechanical and electrical characteristics of a grid-tied PMSG wind power system. Moreover, it can be used to educate students or engineers to understand the operation of grid-tied PMSG wind power systems.

\section{REFERENCES}

[1] B. Wu, Y. Lang, N. Zargari, and S. Kouro, Power Conversion and Control of Wind Energy Systems, Hoboken NJ: Wiley, 2011.

[2] M. P. Kazmierkowski, R. Krishnan, and F. Blaabjerg, Control in Power Electronics-Selected Problems, New York: Academic Press, 2002.

[3] K. H. Kim, Y. C. Jeung, D. C. Lee, and H. G. Kim, "Robust control of PMSG wind turbine systems with back-to-back PWM converters," IEEE International Symposium on Power Electronics for Distributed Generation Systems, 2012.

[4] S. Li, T. A. Haskew, R. P. Swatloski, and W. Gathings, "Optimal and direct-current vector control of direct-driven PMSG wind turbines," IEEE Trans. Power Electron., Vol. 27, No. 5, pp. 2325-2337, May 2012.

[5] F. Kendouli, K. Abed, K. Nabti, H. Benalla, and B. Azoui, "High performance PWM converter control based PMSG for variable speed wind turbine," International Conference on Renewable Enegies and Vehicular Technology, pp. 502-507, 2012.

[6] S. Tammaruckwattana and K. Ohyama, "Experimental verification of variable speed wind power generation system using permanent magnet synchronous generator by wind turbine emulator," in Proc. IECON, pp. 5827-5832, 2012.

[7] D. M. Eggleston and F. S. Stoddard, Wind Turbine Engineering Design, Springer, pp. 15-64, 1987.
[8] K. Ohyama and T. Nakashima, "Wind turbine emulator using wind turbine model based on blade element momentum theory," International Symposium on Power Electronics, Electrical Drives, Automation and Motion T. SPEEDAM, pp. 762-765, 2010.

[9] S. Tammaruckwattana and K. Ohyama, "Modeling and simulation of permanent magnet synchronous generator wind power generation system using boost converter circuit," in Proc. EPE, pp. 1-10, 2013.

[10] S. Tammaruckwattana and K. Ohyama, "Experimental verification of variable speed wind power generation system using permanent magnet synchronous generator by boost converter circuit," in Proc. IECON, pp. 7157-7162, 2013.

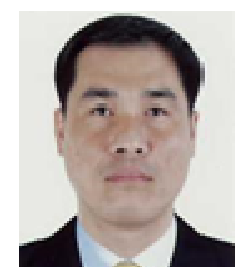

Sirichai Tammaruckwattana received his B.Eng. and M.Eng. in Electrical and Control Engineering from King Mongkut's Institute of Technology Ladkrabang, Bangkok, Thailand, in 2001 and 2005, respectively. In December 2005, he joined the Department of Control and Mechatronic Engineering, King Mongkut's Institute of Technology Ladkrabang, Bangkok, Thailand, as a lecturer. He is currently working toward a Ph.D. degree at the Department of Electrical Engineering, Fukuoka Institute of Technology, Fukuoka, Japan. He is currently engaged in research on variable speed wind power generation system using permanent magnet synchronous generator by natural wind.

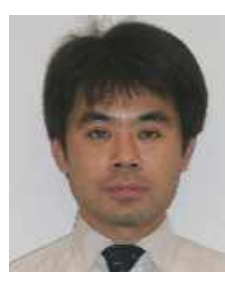

Kazuhiro Ohyama received his B.Eng. in Electrical Engineering and his M.Eng. and D.Eng. from Kagoshima University, Kagoshima, Japan, in 1993, 1995, and 1998, respectively. He was a visiting scholar at the University of Nottingham, Nottingham, U.K., from 1998 to 1999. In April 1999, he joined the Department of Electrical Engineering, Fukuoka Institute of Technology, Fukuoka, Japan, as a lecturer. In April 2002, he was promoted to associate professor. Then, in April 2009, he was promoted to professor. He is currently engaged in the study of $\mathrm{AC}$ motor drives.

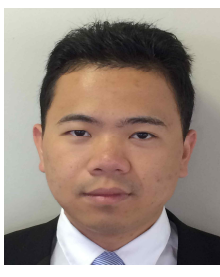

Chenxin Yue received his B.Eng. in Electrical Engineering from the Nanjing University of Science and Technology, Nanjing, China, in 2012. He is currently working toward his master's degree at the Department of Electrical Engineering, Fukuoka Institute of Technology, Fukuoka, Japan. He is currently engaged in research on variable speed wind power generation system. 